\title{
Educación patrimonial y competencias pedagógicas investigativas en estudiantes de educación superior tecnológica de Lima, Perú
}

\author{
Heritage education and research pedagogical competences in students \\ of technological higher education in Lima, Peru
}

\section{Ensino patrimonial e competências pedagógicas de pesquisa em estudantes de ensino tecnológico em Lima, Peru}

\author{
ISSN 1688-9304 - DOI: https://doi.org/10.18861/cied.2020.11.1.2943
}

Iván Ernesto Quijano Araníbar ${ }^{* 1}$

ORCID: https://orcid.org/0000-0003-2264-1186

Fecha de recibido: 19/02/2019

Fecha de aprobado: 04/04/2019

\begin{abstract}
Resumen
El objetivo del presente estudio fue demostrar que el empleo de la educación patrimonial fortalece las competencias pedagógicas investigativas del estudiantado. El enfoque de investigación es cuantitativo y el tipo explicativo. Se ha elegido el diseño cuasiexperimental con post-prueba únicamente y grupo control. La muestra es de tipo no probabilística y está constituida por 36 educandos del $4 .^{\circ}$ ciclo de la carrera de Guía Oficial de Turismo, de los cuales 20 son del turno mañana (grupo experimental) y 16 del turno noche (grupo control). Se aplicó la encuesta directa y la observación participante a través de dos instrumentos: el cuestionario A1 y la lista de cotejo B1, respectivamente. De igual modo, para el análisis se utilizó el programa IBM SPSS para obtener el valor chi-cuadrado $\left(X^{2}\right)$ de cada ítem. Los resultados demuestran que el uso de la educación patrimonial no solo incentiva la práctica de los derechos y deberes cívico-patrimoniales sino también fortalece las competencias pedagógicas investigativas de los discentes del curso de patrimonio cultural.
\end{abstract}

Palabras clave: educación cívica, educación patrimonial, educación superior, competencias, Perú.

\begin{abstract}
The aim of the study was to show that the use of patrimonial education develops students' research competences. The research approach is quantitative and of explanatory type, of quasi-experimental design, with post-test only and a control group. A non-probabilistic sampling was used, which consisted of 36 students of the 4th cycle of the career of official tour guide. Of said group, 20 students were selected from the morning shift (experimental group) and 16 from the night shift (control group). The direct survey and the participant observation were applied through two instruments; the A1 questionnaire and the B1 comparison list, respectively. As regards data analysis, IBM SPSS software was used to obtain the chi-square value (X2) of each item. The results show that the use of patrimonial education not only encourages the practice of patrimonial civic rights and duties, but also develops the research and pedagogical competences of the students of the Cultural Heritage course.
\end{abstract}

Keywords: civic education, heritage education, higher education, competences, Peru. 


\section{Resumo}

A pesquisa tem como objetivo demonstrar que o uso do ensino patrimonial fortalece as competências pedagógicas de pesquisa dos alunos. A abordagem da pesquisa é quantitativa e o tipo é explicativo. O projeto é quase experimental, apenas com pós-teste e grupo de controle. A amostra é não probabilística. É composta por 36 alunos do $4^{\circ}$ ciclo do curso de guia turístico oficial, sendo 20 da turma da manhã (grupo experimental) e 16 da turma da noite (grupo controle). A pesquisa direta foi utilizada através do questionário A1 e a observação do participante através do checklist B1. De igual maneira, foi utilizado para a análise o aplicativo IBM SPSS para obter o valor qui-quadrado (X2) de cada item. Os resultados mostram que o uso do ensino patrimonial fortalece as competências pedagógicas de pesquisa dos alunos do curso de patrimônio cultural e incentiva a prática de direitos e deveres cívicos do patrimônio.

Palavras chave: ensino cívico, ensino patrimonial, ensino superior, competências, Peru.

\section{Introducción}

El sistema peruano de educación superior se encuentra en un período de cambio centrado en mejorar los estándares de calidad para una formación integral del alumnado (Quijano, 2018). Esta medida, entre otras, ha sido tomada debido a la ausencia de competencias pedagógicas investigativas (CPI) dado que la mayoría de los docentes y discentes son solo consumidores de conocimientos (Lazo, 2013), realidad evidenciada en el bajo número de publicaciones científicas (Miyahira, 2009). En este contexto emerge la Ley Universitaria N. ${ }^{\circ}$ 30220 (del 8 de julio de 2014) fundamentada en el cultivo del saber superior. Por tanto tiene un rol primordial la investigación formativa, una metodología activa que permita fortalecer las competencias vinculadas al ejercicio de la investigación multidisciplinaria desde los primeros ciclos hasta la obtención del grado o título profesional (Cerda, 2007). A pesar de ser conscientes de que la mayoría de los egresados "no harán investigación como su actividad principal, sin embargo, deben tener la capacidad de hacer investigación y realizarla cuando sea necesaria en su actividad laboral" (Miyahira, 2009, p.120).

Dentro del marco de la investigación formativa, en el sistema educativo latinoamericano se han aplicado métodos activos tales como el aprendizaje basado en problemas (ABP), estudios de casos y seminarios entre los más importantes, con el fin de desarrollar una actitud científica expresada en el fortalecimiento del pensamiento crítico y de las CPI en el alumnado (Cerda, 2007; Miyahira, 2009; Parra, 2004; Restrepo, 2002). Igualmente, se ha buscado que el alumnado aprendiera a sistematizar y a comunicar sus resultados de investigación (Calderón, 2015) así como a impulsar el trabajo en equipo para reforzar las relaciones interpersonales y promover la responsabilidad de su aprendizaje (Poot, 2013). En esta misma línea se suma la educación patrimonial en Europa, gracias al uso de estrategias didácticas con resultados de similar importancia. Entre ellas podemos citar la enseñanza de la arqueología como herramienta educativa dado que consolida en los educandos las competencias de un investigador científico al utilizar el método hipotéticodeductivo (Santacana, 2018). Un caso similar, adaptado a la realidad educativa peruana, se focaliza en el empleo de la arqueología experimental, un recurso didáctico especializado cuyo objetivo es dinamizar la interacción educativa y reconstruir la cultura material arqueológica mediante la aplicación del método científico por parte del alumnado (Quijano, 2018; 2019).

Asimismo, la educación patrimonial busca el desarrollo de las competencias cívicopatrimoniales tal como se manifiesta en el proyecto educativo-arqueológico de Bardavio y Mañé (2017) en el Campo de la Noguera dado que impulsa la comprensión y reflexión sobre la realidad histórico-social así como las competencias pedagógicas para la toma de decisiones en busca de soluciones a problemáticas de su entorno. Todo esto permite a 
los discentes emitir juicios éticos y ejercer sus derechos y deberes patrimoniales. De igual forma se destaca el Proyecto Educativo de Adopción de Monumentos (PEAM) de Bardavio y González (2012) ya que pretende que cada institución educativa adopte un monumento para construir un vínculo entre comunidades (escolar, político-cultural, científica, etc.) por medio del patrimonio cultural con el objetivo de cuidarlo, protegerlo, difundirlo y revalorarlo.

Tomando estas ideas de cabecera se plantea el siguiente objetivo general: demostrar que el empleo de la educación patrimonial fortalece las CPI de los educandos de la asignatura de Patrimonio Cultural.

Por consiguiente, se han propuesto los siguientes objetivos específicos:

- Determinar que la enseñanza del patrimonio cultural local mejora la dimensión cognitiva de las CPI del estudiantado.

- Establecer que la didáctica del patrimonio cultural desarrolla la dimensión procedimental de las CPI del estudiantado.

- Demostrar que el civismo fortalece la dimensión actitudinal de las CPI del estudiantado.

\section{Marco teórico}

\section{La educación patrimonial y su didáctica}

Cuenca, Estepa y Martín (2011) definen a la educación patrimonial como una corriente encargada de realizar propuestas educativas y/o didácticas de corte investigativo, interdisciplinar y sociocrítico para desarrollar valores identitarios en el alumnado y formar ciudadanos comprometidos con su realidad sociocultural e histórica. Por lo tanto este enfoque se inicia con la investigación propiamente dicha, dirigida por especialistas, con la finalidad de alcanzar una interpretación científica de los elementos patrimoniales. A partir de aquí se bifurcan dos ámbitos: uno de difusión académica (élite) y otro de comunicación social (no especializado). En consecuencia, la didáctica del patrimonio desempeña un papel determinante en la socialización del patrimonio (Cuenca, 2014). Asimismo López y Cuenca (2014) precisan que la educación del patrimonio es todo acto donde se aprenden los elementos patrimoniales. No obstante puede o no tener intencionalidad didáctica y prescindir de una investigación patrimonial stricto sensu. En este sentido el aprendizaje patrimonial se da en niveles diferenciados como el básico, sujeto a aquellos aprendizajes patrimoniales indirectos carentes de intención educativa como se practica en la educación informal, y el complejo, que cuenta con una planificación educativa en la dimensión formal y no formal.

En lo referente a las actividades patrimoniales Coma (2011) ha sistematizado 15 modelos educativos con el objetivo de contar con un corpus teórico para que los educadores apliquen estas recetas a diversas realidades culturales. Por ende, todo modelo permite interpretar el patrimonio, vale decir, decodificarlo e identificar los mensajes implícitos de los bienes culturales para transmitir contenidos conceptuales y procedimentales y así fomentar una educación actitudinal. Entre ellos se encuentran: el modelo de investigación, el taller, el kit móvil, la actividad-aula, etc. 


\section{Las competencias pedagógicas investigativas (CPI)}

El concepto de competencia comprende integralmente tres dimensiones: el saber por sí mismo, es decir la comprensión del conocimiento, el saber hacer, o sea el uso de los nuevos conocimientos con determinadas habilidades y destrezas y el ser, vale decir el rasgo actitudinal y comportamental propio del educando (Pérez, 2012). Otros autores como Cázares y Cuevas (2007) añaden una dimensión denominada el saber transferir, entendida como la toma de decisiones de los educandos para adaptarse y dar solución a nuevos escenarios problemáticos. En definitiva, las competencias son los aprendizajes de contenidos conceptuales y/o procedimentales para aprovecharlos en determinados contextos a través de las habilidades, talentos y destrezas del alumnado. De igual manera, estarán cargadas de elementos subjetivos y valorativos que guiarán su praxis (Quijano, 2019).

A pesar de ser complementarias existen diferencias entre las competencias en la formación para la investigación y para la investigación formativa. En el primer caso se busca que el alumnado domine y aplique el método científico para la producción del conocimiento nuevo, validado por una comunidad científica. Esto se logra a partir de los semilleros con líneas de investigación definidas (Miyahira, 2009). Pérez (2012) menciona entre 25 y 50 capacidades y habilidades por cada dimensión dentro de las competencias investigativas. En cambio, cuando se hace alusión a las competencias pedagógicas de la investigación formativa se fomenta la familiarización, pericia y base para el desarrollo de algunas de las capacidades y habilidades demandadas en el primer caso en vista de que el educando, con las experiencias previas, en un futuro próximo podrá explotar en un máximo esplendor sus competencias investigativas (Quijano, 2019).

De tal modo, "la investigación formativa desarrolla en los estudiantes las capacidades de interpretación, de análisis y de síntesis de la información, y de búsqueda de problemas no resueltos, el pensamiento crítico y otras capacidades como la observación, descripción y comparación; todas directamente relacionadas también con la formación para la investigación" (Miyahira, 2009, p. 121).

Por su parte, Cerda (2007) ha sistematizado las competencias básicas y pedagógicas de la investigación formativa que han sido utilizadas en nuestra investigación:

- Capacidad para hacer preguntas y formular interrogantes.

- Capacidad para identificar y definir problemas.

- Capacidad para la heurística: selección y sistematización de la información.

- Capacidad para describir, analizar e interpretar.

- Capacidad para elaborar y redactar informes de investigación.

\section{Metodología}

\section{Enfoque, tipo y diseño de investigación}

La investigación es de enfoque cuantitativo y de tipo explicativo. Se empleó el diseño cuasiexperimental de corte transversal con post-prueba únicamente y grupo control para conocer las diferencias significativas entre los grupos intactos (Hernández, Fernández \& Baptista, 2014). Esto se debe a la viabilidad y naturaleza de la investigación puesto que los discentes pertenecen a turnos distintos (mañana y noche), hecho que imposibilitó la asignación al azar para emparejar los grupos al inicio de la investigación porque ningún discente estaba dispuesto a acudir al curso de patrimonio cultural en un horario distinto al de su matrícula. 


\section{Población y muestra}

La población consiste en un grupo de 40 educandos del $4 .^{\circ}$ ciclo del Instituto Superior Tecnológico CEPEA del distrito de Pueblo Libre, Lima-Perú, del turno mañana y noche de la carrera de Guía Oficial de Turismo, matriculados en el curso de patrimonio cultural durante el segundo semestre académico de 2018. El alumnado es mixto y su edad oscila entre los 17 y los 28 años.

Por su parte, el tamaño de la muestra ha sido determinado con la ayuda del programa estadístico Decision Analyst STATS ${ }^{\text {TM }} 2.0$ y se consideró un margen de error de $5 \%$ y un nivel de confianza de 95\%. La muestra de estudio está constituida por 36 alumnos de ambos turnos. Incluso, para precisar la muestra de grupos se procedió manualmente por medio del uso de la fórmula señalada por los especialistas (Ñaupas, Mejía, Novoa \& Villagómez, 2014) y se definió en 20 estudiantes para el turno mañana (grupo experimental) y 16 para el turno noche (grupo control) (ver tabla 1).

Tabla 1. Población (N) y muestra de estudio (n)

\begin{tabular}{|c|c|c|c|}
\hline $\begin{array}{c}\text { Unidad de análisis / } \\
\text { Turno }\end{array}$ & Mañana & Noche & Total \\
\hline $\mathrm{N}$ & 22 & 18 & 40 \\
\hline $\mathrm{n}$ & 20 & 16 & 36 \\
\hline
\end{tabular}

Fuente: elaboración propia.

Con respecto a la representatividad, la muestra es de tipo no probabilístico y se aplicó el muestreo por cuotas, dado que "consiste en formar grupos, estratos, clases de individuos por alguna característica en común: sexo, edad, grupos ocupacionales, nivel de instrucción, etc. pero no aleatoriamente sino a criterio del investigador" (Ñaupas et al., 2014, p.253). De tal modo se han considerado discentes con una edad que oscila entre los 18 y los 24 años.

\section{Técnicas e instrumentos}

Las técnicas seleccionadas fueron la encuesta y la observación. Por esta razón se elaboraron dos instrumentos de recolección de datos (post-prueba): un cuestionario A1, con preguntas cerradas con escalonamiento de tres categorías (siembre, a veces y nunca) y constituido por 9 ítems (1-9), y una lista de cotejo B1, con preguntas dicotómicas (sí y no) y compuesta por 11 ítems (10-20) (ver tabla 2). 


\section{Tabla 2. Ítems de los instrumentos A1 y B1 (Post-test)}

\begin{tabular}{|c|}
\hline \\
\hline $\begin{array}{l}\text { 1. ¿Usted ha entendido el concepto de patrimonio cultural como una construcción socio-cultural? } \\
\text { 2. ¿Ha reconocido y comprendido la historia y diversidad patrimonial de Pueblo Libre? } \\
\text { 3. ¿Usted empleó el patrimonio cultural de Pueblo Libre como objeto de estudio a desarrollar } \\
\text { durante el semestre académico? } \\
\text { 4. ¿Ha identificado, clasificado e interpretado el patrimonio cultural del Perú dentro y fuera de aula? } \\
\text { 5. ¿Usted ha construido su propio conocimiento por medio de actividades participativas que } \\
\text { fomentan la investigación patrimonial? } \\
\text { 6. ¿Ha comunicado sus resultados e informes finales de investigación a la comunidad educativa? } \\
\text { 7. ¿Usted reflexiona sobre la importancia, cuidado, conservación y difusión de la historia de Pueblo } \\
\text { Libre y de sus elementos patrimoniales? } \\
\text { 8. ¿Participa con responsabilidad ejerciendo activamente sus derechos y deberes ciudadanos } \\
\text { respecto al patrimonio cultural? } \\
\text { 9. ¿Usted respeta la diversidad del patrimonio cultural (bienes, actividades y creencias) manifestada } \\
\text { dentro y fuera de la comunidad educativa? }\end{array}$ \\
\hline \\
\hline $\begin{array}{l}\text { 10. Sintetiza información relevante sobre el patrimonio cultural: definición, características, valores, } \\
\text { clases e importancia. } \\
\text { 11. Reconoce el dinamismo de la ciencia (ensayo-error) a través de su puesta en práctica. } \\
\text { 12. Identifica el problema de investigación a partir de su realidad histórico-patrimonial. } \\
\text { 13. Estructura el método hipotético-deductivo a partir del conocimiento de sus fases y/o etapas. } \\
\text { 14. Discriminó y sistematizó información relevante sobre el patrimonio cultural. } \\
\text { 15. Ha diseñado los instrumentos de recolección de datos sobre el patrimonio cultural de Pueblo } \\
\text { Libre. } \\
\text { 16. Aplicó los instrumentos de recolección de datos por medio de encuestas y entrevistas dirigidas } \\
\text { a la comunidad educativa. } \\
\text { 17. Ha elaborado y redactado informes a partir de los resultados de investigación. } \\
\text { 18. Ha formulado preguntas y puntos de vista de manera asertiva durante el curso de patrimonio } \\
\text { cultural. } \\
\text { 19. Trabajó en equipo junto a sus pares de clase de manera ética con la finalidad de aprender } \\
\text { colectivamente. } \\
\text { 20. Promovió la tolerancia y la sana convivencia en la comunidad educativa a pesar de las diferencias } \\
\text { culturales. }\end{array}$ \\
\hline
\end{tabular}

Fuente: elaboración propia.

Para precisar la validez de ambos instrumentos se optó por la modalidad de juicio de expertos conformado por especialistas en metodología quienes determinaron la pertinencia de los ítems en función de la claridad, objetividad, actualidad, organización, suficiencia, intencionalidad, consistencia, coherencia y metodología.

Posteriormente se aplicaron las técnicas de encuesta y observación en la semana 14 de la programación curricular, en paralelo al cierre de ciclo del segundo semestre académico de 2018. Por este motivo se encuestó directamente a los educandos del grupo control y del grupo experimental mediante el cuestionario A1, administrado colectivamente en el aula y con una duración no mayor a 30 minutos. Asimismo los profesores de turno de ambos grupos de estudio utilizaron la observación directa participante con un nivel de integración parcial, pues emplearon el instrumento B1 en el taller cultural N. ${ }^{\circ} 3$ del estudiantado. Por último, la información recolectada por medio de los instrumentos ha sido sistematizada en una matriz de datos del programa Microsoft Excel para luego ser exportada al programa estadístico IBM SPSS 20.0 con la finalidad de ser analizada. 


\section{Dimensiones}

Los instrumentos elaborados (A1 y B1) han sido diseñados a través de las variables independiente (educación patrimonial) y dependiente (competencias pedagógicas investigativas). Cada una presenta un conjunto de dimensiones e indicadores que se contemplan en la tabla 3.

Tabla 3. Variables, dimensiones, indicadores e instrumentos con sus respectivos ítems

\begin{tabular}{|c|c|c|c|c|}
\hline v & Dimensión & Indicadores & Ítem & I \\
\hline \multirow{9}{*}{ 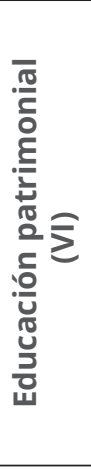 } & \multirow{3}{*}{$\begin{array}{l}\text { Enseñanza del } \\
\text { patrimonio } \\
\text { cultural local }\end{array}$} & Entiende el concepto de patrimonio cultural. & 1 & \multirow{9}{*}{ 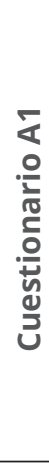 } \\
\hline & & Reconoce y comprende la realidad histórico-cultural. & 2 & \\
\hline & & Emplea el patrimonio cultural como objeto de estudio. & 3 & \\
\hline & \multirow{3}{*}{$\begin{array}{l}\text { Didáctica del } \\
\text { patrimonio } \\
\text { cultural }\end{array}$} & Identifica, clasifica e interpreta el patrimonio cultural. & 4 & \\
\hline & & Construye su conocimiento. & 5 & \\
\hline & & Comunica los resultados. & 6 & \\
\hline & \multirow{3}{*}{ Civismo } & Reflexiona sobre la realidad histórica y cultural local. & 7 & \\
\hline & & Participa de los derechos y deberes cívico-patrimoniales. & 8 & \\
\hline & & Respeta la diversidad patrimonial. & 9 & \\
\hline \multirow{11}{*}{ 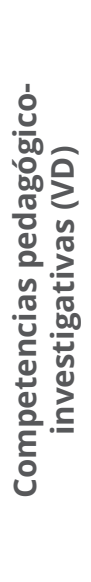 } & \multirow{4}{*}{$\begin{array}{c}\text { Cognitiva } \\
\text { (Saber) }\end{array}$} & Sintetiza información relevante. & 10 & \multirow{11}{*}{ 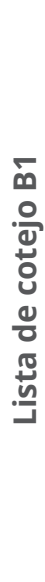 } \\
\hline & & Reconoce el dinamismo de la ciencia y del patrimonio. & 11 & \\
\hline & & Identifica el problema de investigación. & 12 & \\
\hline & & Estructura el método científico. & 13 & \\
\hline & \multirow{4}{*}{$\begin{array}{l}\text { Procedimental } \\
\text { (Saber hacer) }\end{array}$} & Discrimina y sistematiza información. & 14 & \\
\hline & & Diseña los instrumentos de recolección de datos. & 15 & \\
\hline & & Aplica los instrumentos de recolección de datos. & 16 & \\
\hline & & Elabora y redacta informes. & 17 & \\
\hline & \multirow{3}{*}{$\begin{array}{l}\text { Actitudinal } \\
\text { (Saber ser) }\end{array}$} & Formula preguntas y puntos de vista de manera asertiva. & 18 & \\
\hline & & Trabaja en equipo con ética. & 19 & \\
\hline & & Promueve la tolerancia y la sana convivencia. & 20 & \\
\hline
\end{tabular}

Fuente: elaboración propia.

\section{Secuencia didáctica}

En la asignatura de Patrimonio Cultural se ha seleccionado el modelo de investigación estructurado por Coma (2011), enmarcado en el nivel complejo de socialización del patrimonio e insertado en el ámbito educativo formal, donde los educandos han utilizado el método hipotético-deductivo con guía y orientación del docente de turno en un contexto educativo peruano. En este marco se realizó una secuencia didáctica conformada por 14 sesiones curriculares para el grupo control y el experimental. Se programaron sesiones semanales con una duración de 3 horas pedagógicas de 50 minutos cada una durante el segundo semestre de 2018. Igualmente, las clases se desarrollaron de manera teórica y práctica a partir del uso de recursos didácticos digitales (documentos en pdf, diapositivas en ppt, medios audiovisuales en mp4, etc.) y talleres culturales bajo el enfoque constructivista. Por su parte, las temáticas y contenidos curriculares fueron los mismos, aunque el grupo experimental aplicó la educación patrimonial con la ayuda del modelo de investigación patrimonial durante todo el semestre académico. El grupo control aprovechó el seminario, 
una estrategia investigativa clásica mas no anacrónica, por su larga trayectoria en la investigación formativa. Según Pimienta (2012), el seminario consiste en la exposición de un tema por parte del estudiantado y permite crear un escenario para el debate y la discusión a profundidad. El mismo requiere del acopio y sistematización de la información para sostener las ideas durante la discusión. El grupo control empleó el seminario en los talleres culturales. A continuación se detallan las actividades de aprendizaje realizadas por el grupo experimental (ver tabla 4).

Tabla 4. Semanas, temas y actividades de aprendizaje del grupo experimental

\begin{tabular}{|c|c|c|}
\hline Semana & Tema & Grupo experimental \\
\hline 1 & $\begin{array}{l}\text { Patrimonio } \\
\text { cultural peruano }\end{array}$ & $\begin{array}{l}\text { - Define el patrimonio cultural como una construcción } \\
\text { - Elaciocultural. } \\
\text { - } \text { patrimonio un organizador visual sobre la definición del } \\
\text { - Discute el estado del patrimonio cultural en la actualidad. }\end{array}$ \\
\hline 2 & $\begin{array}{l}\text { Valores e } \\
\text { importancia } \\
\text { del patrimonio } \\
\text { cultural }\end{array}$ & $\begin{array}{l}\text { - Elabora un organizador visual sobre los valores del } \\
\text { patrimonio cultural y cita ejemplos. } \\
\text { - Reflexiona sobre la importancia del patrimonio cultural en } \\
\text { base a estado y conservación en la actualidad. } \\
\text { - Expone y argumenta su posición sobre la importancia del } \\
\text { patrimonio cultural. }\end{array}$ \\
\hline 3 & $\begin{array}{l}\text { Clases del } \\
\text { patrimonio } \\
\text { cultural }\end{array}$ & $\begin{array}{l}\text { - Procesa información relevante sobre las clases de patrimonio } \\
\text { cultural a través de diapositivas (ppt). } \\
\text { - Clasifica el tipo de patrimonio cultural en base a imágenes en } \\
\text { diapositivas (ppt) sobre el patrimonio cultural peruano y de } \\
\text { Pueblo Libre, Lima. } \\
\text { - Elabora la ficha de registro de elementos patrimoniales de } \\
\text { Pueblo Libre, Lima. }\end{array}$ \\
\hline 4 & $\begin{array}{l}\text { Taller cultural } \\
\text { N. }{ }^{\circ 1}\end{array}$ & $\begin{array}{l}\text { - Identifica y registra in situ los elementos patrimoniales de } \\
\text { Pueblo Libre gracias a la ficha de registro. }\end{array}$ \\
\hline 5 & $\begin{array}{l}\text { La cultura y sus } \\
\text { universales }\end{array}$ & $\begin{array}{l}\text { - Analiza un documental (mp4) sobre la comunidad de Queros } \\
\text { e identifica sus elementos universales culturales. } \\
\text { - Reflexiona sobre la patrimonialización de la cultura Queros y } \\
\text { sus implicancias. } \\
\text { - Formula interrogantes y preguntas sobre el patrimonio } \\
\text { cultural de Pueblo Libre, Lima. }\end{array}$ \\
\hline 6 & $\begin{array}{l}\text { Patrimonio } \\
\text { cultural material } \\
\text { mueble }\end{array}$ & $\begin{array}{l}\text { - Identifica objetos didácticos (cerámicas, mates, etc.) e } \\
\text { imágenes insertadas en diapositivas (ppt) sobre el patrimonio } \\
\text { cultural material mueble. } \\
\text { - Elabora un organizador visual sobre la definición y } \\
\text { características del patrimonio cultural material mueble. } \\
\text { - Busca y discrimina información relevante sobre el patrimonio } \\
\text { cultural material de Pueblo Libre previamente registrado en } \\
\text { el trabajo de campo. }\end{array}$ \\
\hline 7 & $\begin{array}{l}\text { Patrimonio } \\
\text { cultural material } \\
\text { inmueble }\end{array}$ & $\begin{array}{l}\text { - Identifica imágenes insertadas en diapositivas (ppt) sobre el } \\
\text { patrimonio cultural material inmueble. } \\
\text { - Analiza un documental (mp4) sobre los inmuebles } \\
\text { patrimoniales y discute sobre la importancia de un } \\
\text { patrimonio vivo. } \\
\text { - Busca y discrimina información relevante sobre el patrimonio } \\
\text { cultural de Pueblo Libre previamente registrado en el trabajo } \\
\text { de campo. }\end{array}$ \\
\hline
\end{tabular}




\begin{tabular}{|c|c|c|}
\hline 8 & $\begin{array}{l}\text { Patrimonio } \\
\text { cultural industrial }\end{array}$ & $\begin{array}{l}\text { - Realiza una lectura crítica sobre un artículo especializado } \\
\text { sobre el patrimonio industrial del Perú. } \\
\text { - Propone el problema de investigación y se establecen los } \\
\text { objetivos en una matriz. } \\
\text { - Formula las hipótesis de investigación en una matriz. }\end{array}$ \\
\hline 9 & $\begin{array}{l}\text { Patrimonio } \\
\text { cultural } \\
\text { documental y } \\
\text { subacuático }\end{array}$ & $\begin{array}{l}\text { - Elabora un organizador visual sobre la definición y clases del } \\
\text { patrimonio cultural documental y subacuático. } \\
\text { - Analiza un documental (mp4) sobre el Archivo General de la } \\
\text { Nación del Perú y reflexiona sobre su importancia. } \\
\text { - Selecciona las técnicas de recolección de datos y diseña los } \\
\text { instrumentos. }\end{array}$ \\
\hline 10 & $\begin{array}{l}\text { Taller cultural } \\
\mathrm{N} .{ }^{\circ} 2\end{array}$ & $\begin{array}{l}\text { - Aplica a la comunidad educativa (educadores, alumnos, } \\
\text { personal administrativo, etc.) los instrumentos de recolección } \\
\text { de datos. }\end{array}$ \\
\hline 11 & $\begin{array}{l}\text { Patrimonio } \\
\text { cultural } \\
\text { inmaterial I }\end{array}$ & $\begin{array}{l}\text { - Analiza un documental (mp4) sobre el caballito de totora y } \\
\text { discute sobre la importancia de un patrimonio vivo. } \\
\text { - Describe, analiza e interpreta los resultados de la } \\
\text { investigación para establecer sus conclusiones. }\end{array}$ \\
\hline 12 & $\begin{array}{l}\text { Patrimonio } \\
\text { cultural } \\
\text { inmaterial II }\end{array}$ & $\begin{array}{l}\text { - Identifica los principales mitos y leyendas prehispánicos } \\
\text { mediante una lectura crítica de las crónicas y reflexiona sobre } \\
\text { su simbolismo. } \\
\text { - Elabora una escenificación teatral de un mito o leyenda } \\
\text { prehispánicos por medio de una lectura designada. } \\
\text { - Selecciona los medios de divulgación de la investigación } \\
\text { patrimonial. }\end{array}$ \\
\hline 13 & $\begin{array}{l}\text { El Perú y su } \\
\text { diversidad } \\
\text { cultural }\end{array}$ & $\begin{array}{l}\text { - Realiza una lectura crítica de un artículo especializado sobre } \\
\text { las múltiples tradiciones del Perú. } \\
\text { - Redacta el informe final de la investigación patrimonial y } \\
\text { elabora los mecanismos de divulgación. }\end{array}$ \\
\hline 14 & $\begin{array}{l}\text { Taller cultural } \\
\text { N. }{ }^{\circ} 3\end{array}$ & $\begin{array}{l}\text { - Expone el informe final y divulga los resultados de la } \\
\text { investigación patrimonial a la comunidad educativa. }\end{array}$ \\
\hline
\end{tabular}

Fuente: elaboración propia.

En cuanto a la investigación patrimonial en Pueblo Libre, ha sido construida en equipos por todos los alumnos del grupo experimental, con guía y orientación del profesor de turno durante el proceso de la investigación.

En primer lugar los discentes han discutido sobre el estado del patrimonio cultural peruano en la actualidad y han reflexionado sobre su importancia (semanas 1 y 2). Asimismo, elaboraron fichas de registro (semana 3) para realizar in situ un reconocimiento y descripción en el Taller N. ${ }^{\circ} 1$ (semana 4) y se registraron 34 elementos patrimoniales en Pueblo Libre. Entre los principales figuran:

- Casa de los Libertadores.

- Casa Hacienda Orbea.

- Cuartel Bolívar.

- Gran Mercado Inca.

- Huaca Julio César Tello.

- Museo Nacional de Arqueología, Antropología e Historia del Perú.

- Museo Larco.

- Santuario Mariano Parroquial.

- Taberna Queirolo. 
Seguidamente surgió un cúmulo de interrogantes y preguntas por parte del alumnado sobre la evidencia empírica apreciada en campo (semana 5). Entre dichas interrogantes figuran por qué el patrimonio cultural de Pueblo Libre está en un estado regular de conservación o por qué está poco difundido. Posteriormente los alumnos se organizaron en equipos para recopilar y seleccionar información relevante sobre los elementos patrimoniales registrados (semanas 6 y 7 ).

Luego de haber contrastado su ficha de registro con la literatura sobre los elementos patrimoniales de Pueblo Libre los educandos, a través de las interrogantes de la semana 5 , seleccionan y proponen el problema de investigación para establecer los objetivos y las hipótesis en una matriz facilitada por el docente (semana 8). De igual modo, se optó por utilizar dos técnicas (encuesta y entrevista) dirigidas a la comunidad educativa (educadores, compañeros de otros ciclos, padres de familia, personal administrativo, etc.) para lo cual se elaboró un cuestionario de preguntas abiertas y cerradas (semana 9). Durante el taller $\mathrm{N} .^{\circ} 2$ todos los educandos del grupo experimental aplicaron el instrumento (semana 10). Sin embargo se seleccionaron al azar los equipos para encuestar y entrevistar a determinados segmentos de la comunidad educativa citada. Luego los alumnos procesaron la información a partir de la descripción e interpretación de resultados con gráficos estadísticos para analizarlos y establecer sus conclusiones (semana 11).

Por último los estudiantes redactaron el informe final de la investigación patrimonial y divulgaron sus resultados con la ayuda de una feria y una exposición dirigidas a toda la comunidad educativa con la finalidad de contrarrestar la problemática estudiada (semanas 12,13 y 14). A manera de síntesis se incorpora la matriz de la investigación patrimonial elaborada por los discentes (ver tabla 5).

Tabla 5: Matriz de la investigación patrimonial en Pueblo Libre, Lima

\begin{tabular}{|l|l|l|l|l|}
\hline Problemas & Objetivos & Hipótesis & Instrumentos & Técnicas \\
\hline ¿La comunidad & Precisar si la & La comunidad & & \\
educativa & comunidad & educativa de CEPEA & Ficha de & Observación \\
de CEPEA se & educativa de & no se identifica & registro & Encuesta \\
identifica con & CEPEA se identifica & con su patrimonio & Cuestionario & Entrevista \\
su patrimonio & con su patrimonio & cultural local por & & \\
cultural local? & cultural local. & falta de difusión. & & \\
\hline
\end{tabular}

Fuente: elaboración propia.

\section{Resultados, análisis y discusión}

Luego de recolectar y sistematizar los datos obtenidos gracias a la aplicación de los instrumentos A1 y B1 se exhiben los resultados de investigación en base a los objetivos específicos y sus respectivas dimensiones.

En función del objetivo específico 1 determinar que la enseñanza del patrimonio cultural local mejora la dimensión cognitiva de las CPI del estudiantado, se describen los siguientes resultados:

\section{* Dimensión enseñanza del patrimonio cultural local}

- En el ítem 1 el 85\% de los alumnos del grupo experimental y el 69\% del grupo control siempre han entendido el concepto de patrimonio cultural como una construcción socio-cultural, mientras que el $5 \%$ y $12 \%$ de los estudiantes del primer y segundo grupo respectivamente nunca entendieron este concepto (gráfico 1). 
- En el ítem 2, el 90\% de los educandos del grupo experimental sostiene que siempre ha reconocido y comprendido la historia y la diversidad patrimonial de Pueblo Libre, mientras que el $57 \%$ y el $31 \%$ de discentes del grupo control indicaron que nunca y algunas veces, respectivamente (gráfico 2 ).

- - De igual manera, en el ítem 3, el 80\% de los educandos del grupo experimental siempre empleó el patrimonio cultural de Pueblo Libre como objeto de estudio a desarrollar durante el semestre académico, mientras que el 75\% de los alumnos del grupo control indicó que nunca lo hacía (gráfico 3).

\begin{tabular}{|l|l|}
\hline $\begin{array}{l}\text { Gráfico 1. Entiende el concepto de patrimonio } \\
\text { cultural }\end{array}$ & $\begin{array}{l}\text { Gráfico 2. Reconoce y comprende la realidad } \\
\text { histórico-cultural local }\end{array}$ \\
\hline $\begin{array}{l}\text { Ítem 1: ¿Usted ha entendido el concepto de } \\
\text { patrimonio cultural como una construcción } \\
\text { socio-cultural? }\end{array}$ & $\begin{array}{l}\text { Ítem 2: ¿Ha reconocido y comprendido la historia } \\
\text { y diversidad patrimonial de Pueblo Libre? }\end{array}$ \\
\hline
\end{tabular}

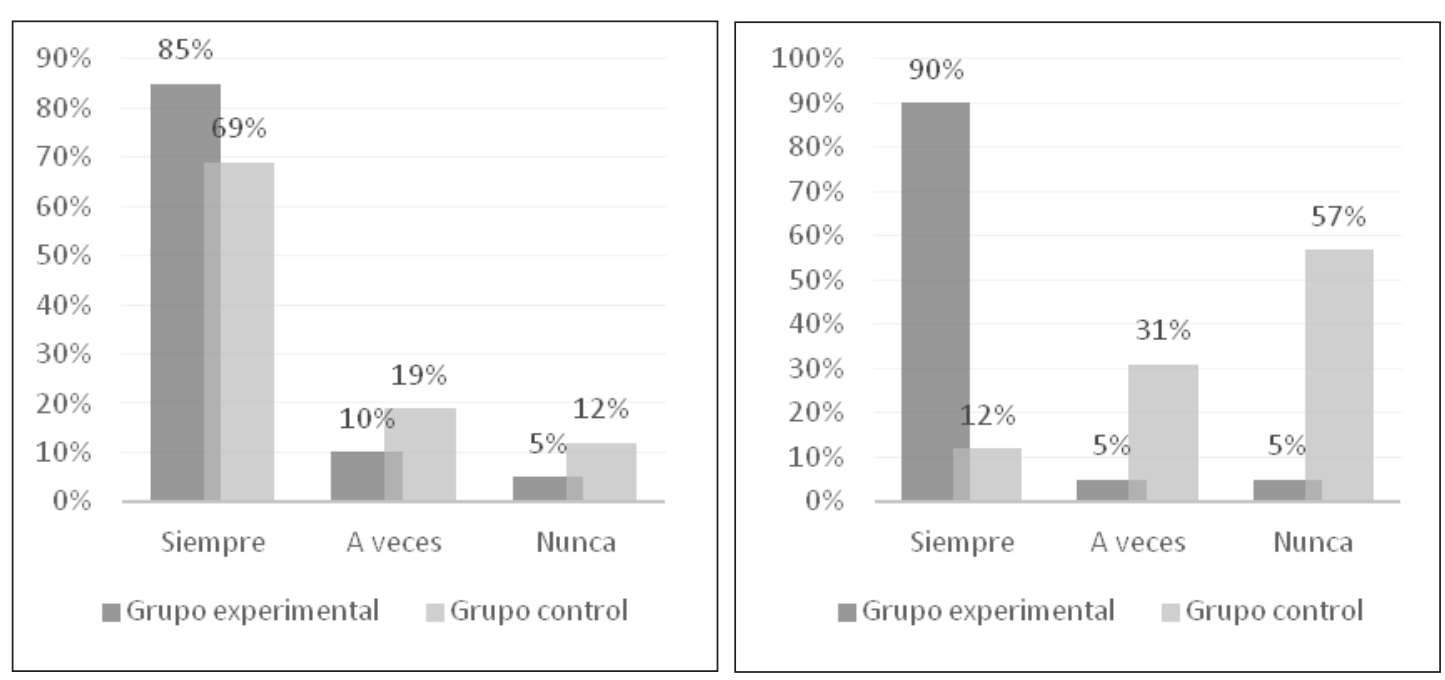

Gráfico 3. Emplea el patrimonio cultural como objeto de estudio

Ítem 3: ¿Usted empleó el patrimonio cultural de Pueblo Libre como objeto de estudio a desarrollar durante el semestre académico?

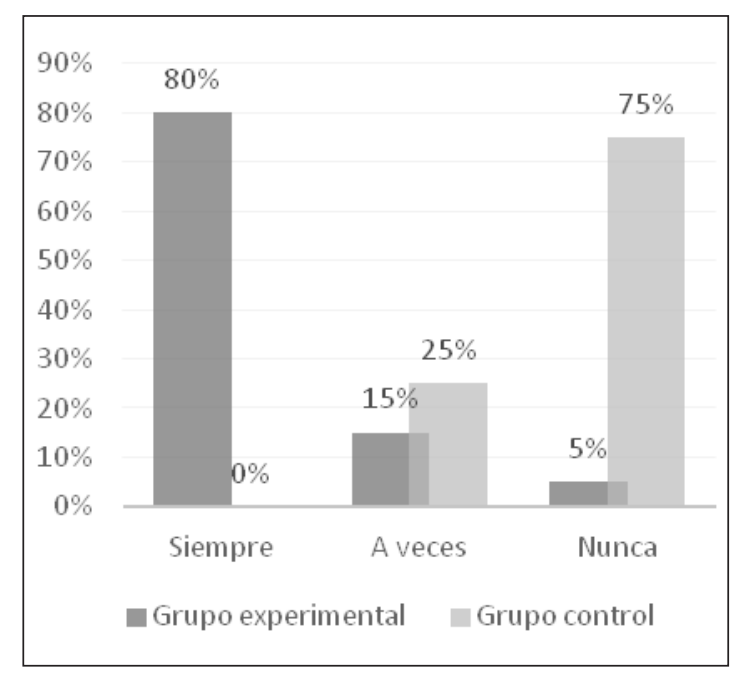




\section{* Dimensión cognitiva (saber)}

- En el ítem 10 el 95\% de los educandos del grupo experimental y el 88\% del grupo control sí sintetizan información relevante sobre el patrimonio cultural. En cambio, el 5\% y el $12 \%$ de los estudiantes del primer y segundo grupo respectivamente se manifestaron negativamente (gráfico 4).

- De igual manera, en el ítem 11, el 85\% de los discentes del grupo experimental sí reconoce el dinamismo de la ciencia (ensayo-error) mediante su puesta en práctica, a diferencia del $100 \%$ de los educandos del grupo control que sostuvo que no lo hacía (gráfico 5).

- De la misma manera, en el ítem 12 el 90\% de los alumnos del grupo experimental sí identifica el problema de investigación por medio de su realidad histórico-patrimonial. Al contrario del $88 \%$ de los educandos del grupo control que precisó que no lo hacía (gráfico 6).

- En el ítem 13, incluso, el 90\% de los estudiantes del grupo experimental sí estructura el método hipotético-deductivo a través del conocimiento de sus fases y/o etapas. Por el contario, el 100\% de los discentes del grupo control determinó que no lo hacía (gráfico 7).

\begin{tabular}{|l|l|}
\hline $\begin{array}{l}\text { Gráfico 4. Sintetiza información } \\
\text { relevante }\end{array}$ & $\begin{array}{l}\text { Gráfico 5. Reconoce el dinamismo de la ciencia y } \\
\text { del patrimonio }\end{array}$ \\
\hline $\begin{array}{l}\text { Ítem 10: Sintetiza información relevante } \\
\text { sobre el patrimonio cultural. }\end{array}$ & $\begin{array}{l}\text { Ítem 11: Reconoce el dinamismo de la ciencia a través } \\
\text { de su puesta en práctica. }\end{array}$ \\
\hline
\end{tabular}

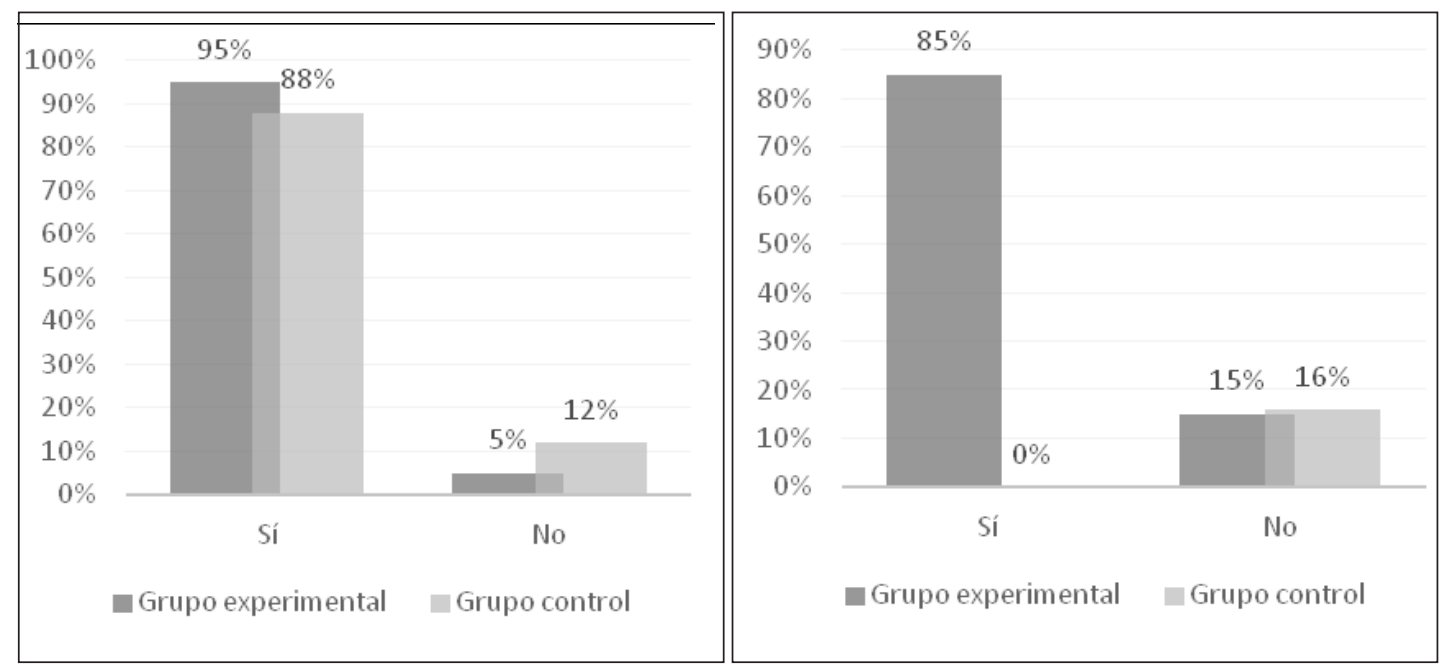

\begin{tabular}{|l|l|}
\hline $\begin{array}{l}\text { Gráfico 6. Identifica el problema de } \\
\text { investigación }\end{array}$ & Gráfico 7. Estructura el método científico \\
\hline $\begin{array}{l}\text { Ítem 12: Identifica el problema de } \\
\text { investigación a partir de su realidad histórico-- } \\
\text { patrimonial. }\end{array}$ & $\begin{array}{l}\text { Item 13: Estructura el método hipotético-deductivo } \\
\text { a partir del conocimiento de sus fases y/o etapas. }\end{array}$ \\
\hline
\end{tabular}

En relación al objetivo específico 2 establecer que la didáctica del patrimonio cultural desarrolla la dimensión procedimental de las CPI del estudiantado, se describen los siguientes resultados: 

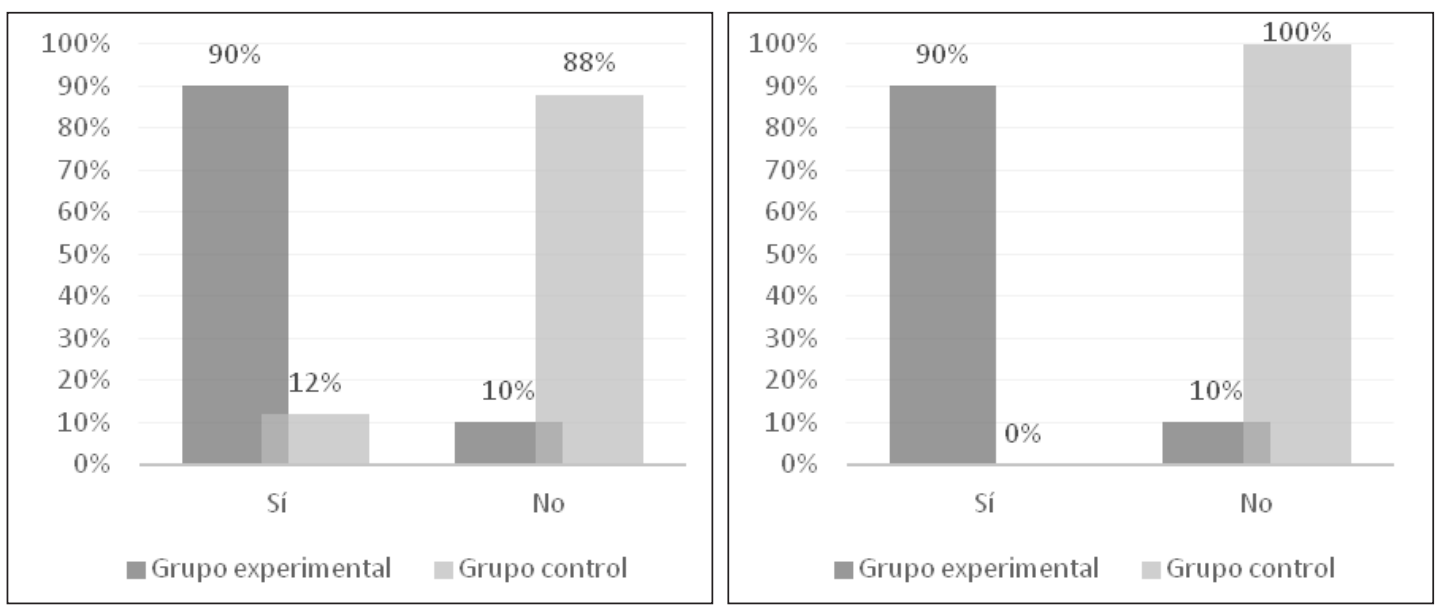

\section{* Dimensión didáctica del patrimonio cultural}

- - En el ítem 4 el 75\% de los educandos del grupo experimental siempre ha identificado, clasificado e interpretado el patrimonio cultural del Perú dentro y fuera de aula, a diferencia del $75 \%$ de los educandos del grupo control que determinó que nunca lo hacía (gráfico 8).

- En el ítem 5 el 80\% de los alumnos del grupo experimental siempre ha construido su propio conocimiento a partir de actividades participativas que fomentan la investigación patrimonial, a diferencia del $75 \%$ de los estudiantes del grupo control que precisó que nunca lo hacía (gráfico 9).

- - En el ítem 6 el 70\% de educandos del grupo experimental siempre ha comunicado sus resultados e informes finales de investigación a la comunidad educativa, a diferencia del $88 \%$ de los discentes del grupo control que precisó que nunca lo hacía (gráfico 10).

\begin{tabular}{|l|l|}
\hline $\begin{array}{l}\text { Gráfico 8. Identifica, clasifica e interpreta el } \\
\text { patrimonio cultural peruano }\end{array}$ & Gráfico 9. Construye su conocimiento \\
\hline $\begin{array}{l}\text { Ítem 4: ¿Ha identificado, clasificado e } \\
\text { interpretado el patrimonio cultural del Perú } \\
\text { dentro y fuera de aula? }\end{array}$ & $\begin{array}{l}\text { Ítem 5: ¿Usted ha construido su propio } \\
\text { conocimiento por medio de actividades } \\
\text { participativas que fomentan la investigación } \\
\text { patrimonial? }\end{array}$ \\
\hline
\end{tabular}
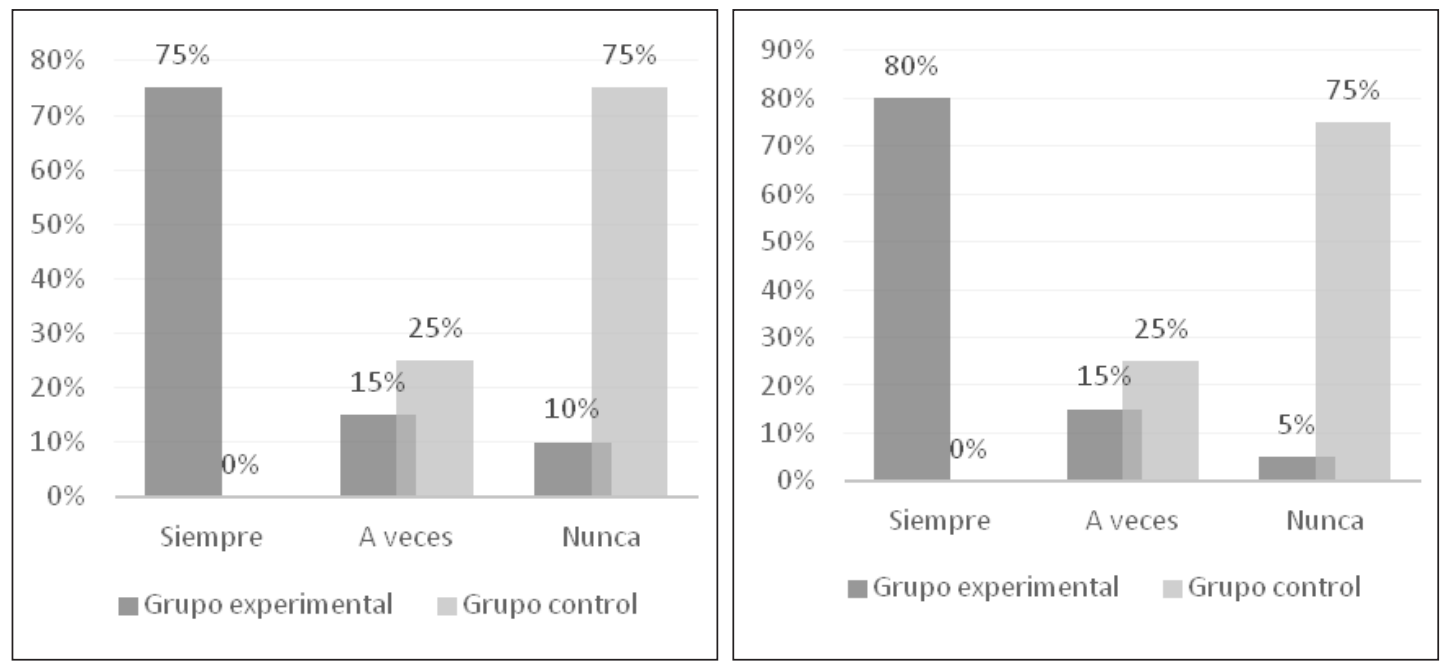


\section{Gráfico 10. Comunica los resultados}

Ítem 6: ¿Ha comunicado sus resultados e informes finales de investigación a la comunidad educativa?

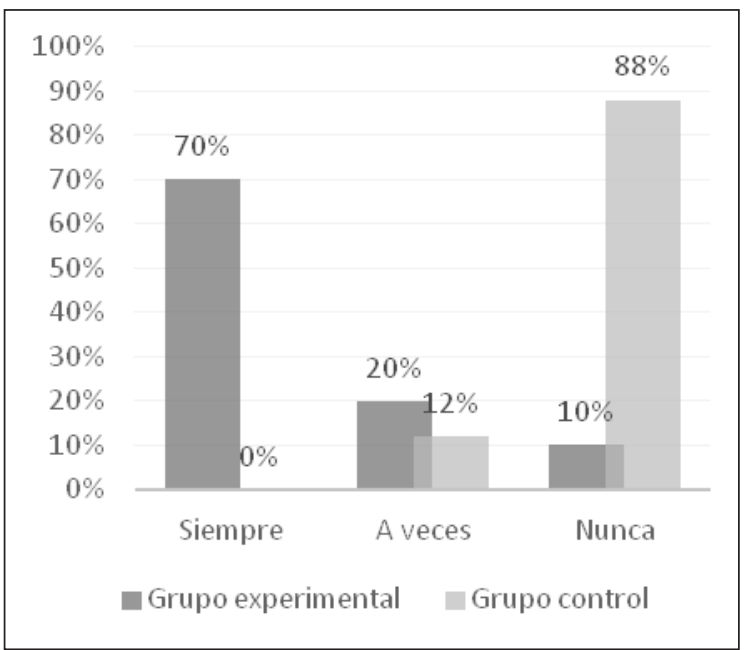

\section{* Dimensión procedimental (saber hacer)}

- En el ítem 14 el 80\% de los educandos del grupo experimental y el 88\% del grupo control sí discriminaron y sistematizaron información relevante sobre el patrimonio cultural, mientras que el $20 \%$ y $12 \%$ de los alumnos del primer y segundo grupo respectivamente no discriminaron ni sistematizaron esta información (gráfico 11).

- En el ítem 15 el 95\% de los estudiantes del grupo experimental sí ha diseñado los instrumentos de recolección de datos sobre el patrimonio cultural de Pueblo Libre, a diferencia del $100 \%$ de los educandos del grupo control que sostuvo que no lo hacía (gráfico 12).

- En el ítem 16, el 95\% de discentes del grupo experimental sí aplicó los instrumentos de recolección de datos con la ayuda de encuestas y entrevistas dirigidas a la comunidad educativa, a diferencia del 100\% de los educandos del grupo control que indicó que no lo hacía (gráfico 13).

- En el ítem 17 el 95\% de los educandos del grupo experimental ha elaborado y redactado informes gracias a los resultados de investigación, mientras que el $100 \%$ de los alumnos del grupo control precisó que no lo hacía (gráfico 14).

\begin{tabular}{|l|l|}
\hline $\begin{array}{l}\text { Gráfico 11. Discrimina y sistematiza } \\
\text { información }\end{array}$ & $\begin{array}{l}\text { Gráfico 12. Diseña los instrumentos de } \\
\text { recolección de datos }\end{array}$ \\
\hline $\begin{array}{l}\text { Ítem 14: Discriminó y sistematizó información } \\
\text { relevante sobre el patrimonio cultural. }\end{array}$ & $\begin{array}{l}\text { Ítem 15: Ha diseñado los instrumentos de } \\
\text { recolección de datos sobre el patrimonio cultural } \\
\text { de Pueblo Libre. }\end{array}$ \\
\hline
\end{tabular}




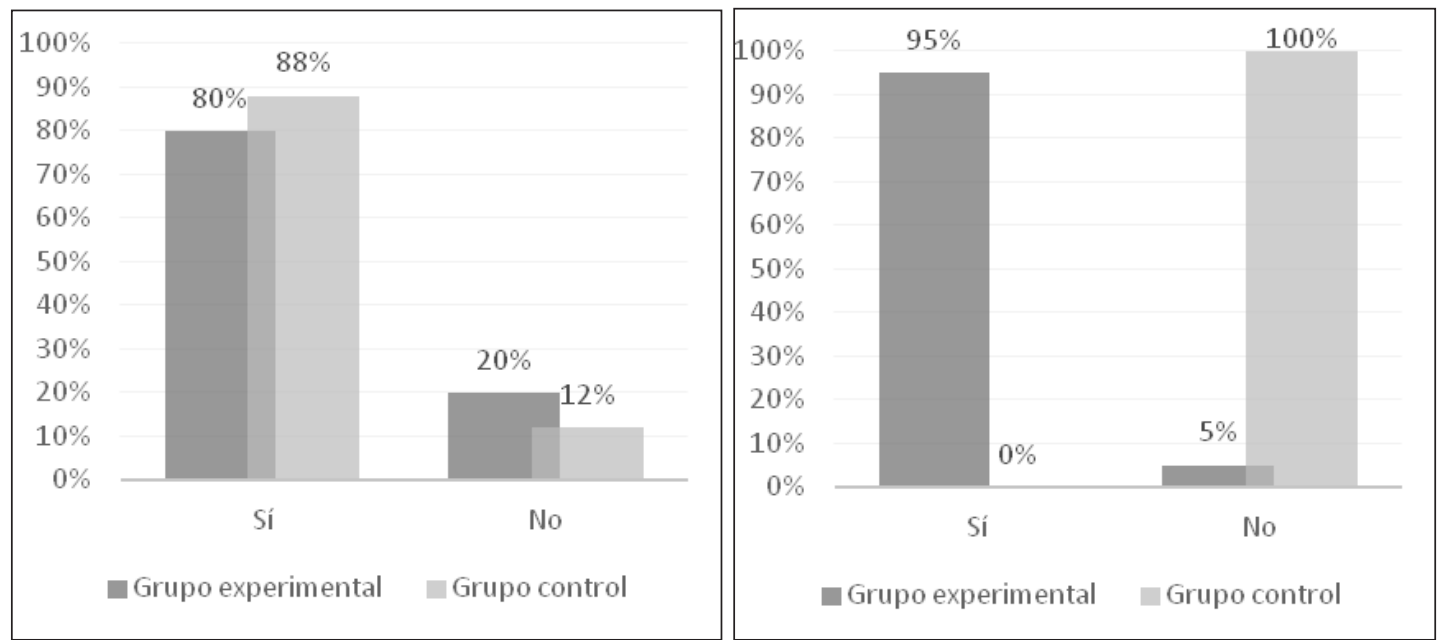

\begin{tabular}{|l|l|}
\hline $\begin{array}{l}\text { Gráfico 13. Aplica los instrumentos de recolección } \\
\text { de datos }\end{array}$ & Gráfico 14. Elabora y redacta informes \\
\hline $\begin{array}{l}\text { Ítem 16: Aplicó los instrumentos por medio de } \\
\text { encuestas y entrevistas dirigidas a la comunidad } \\
\text { educativa. }\end{array}$ & a partir de los laborado y redactado informes \\
\end{tabular}
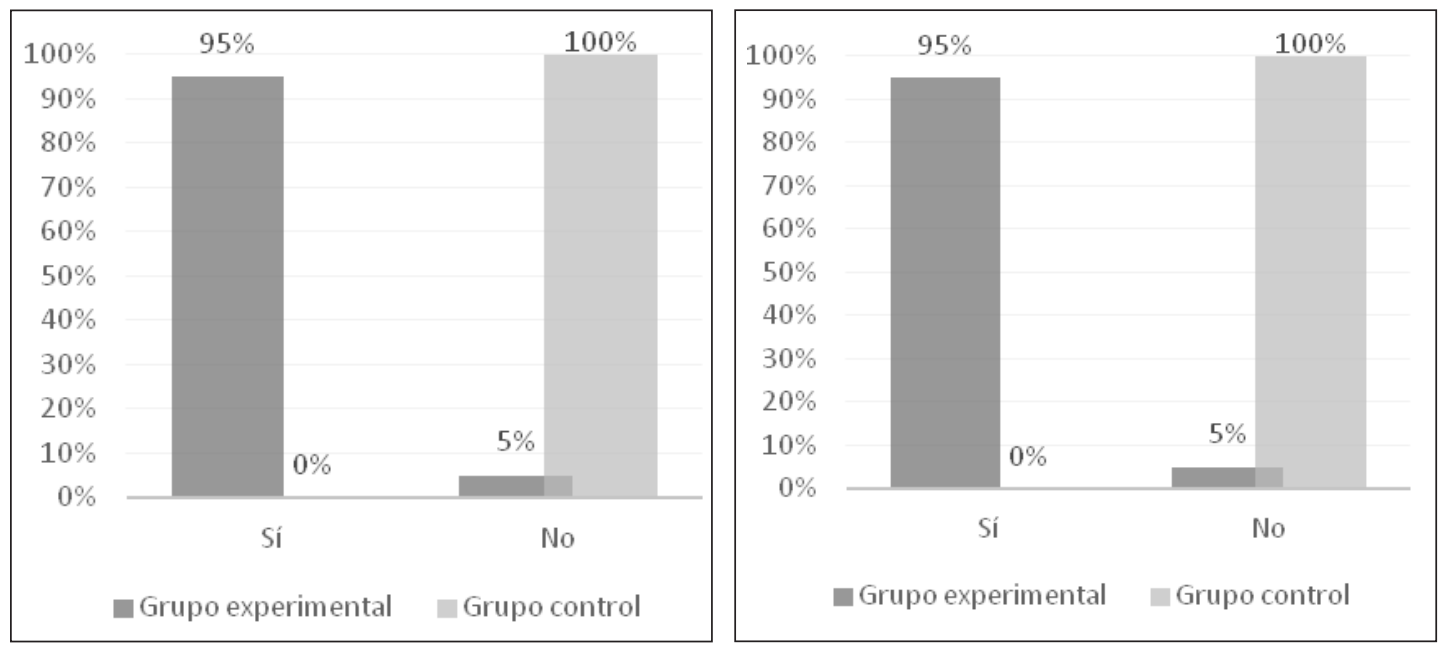

Con respecto al objetivo específico 3 demostrar que el civismo fortalece la dimensión actitudinal de las CPI del estudiantado, se describen los siguientes resultados:

* Dimensión civismo: en el ítem 7, el 60\% y 30\% de los discentes del grupo experimental determinaron que siempre y algunas veces reflexionan sobre la importancia, cuidado, conservación y difusión de la historia de Pueblo Libre y de sus elementos patrimoniales respectivamente. Por el contrario, el $50 \%$ y el $38 \%$ de los educandos del grupo control sostuvieron que nunca y algunas veces, respectivamente (gráfico 15). 
- En el ítem 8 el $60 \%$ de los alumnos del grupo experimental siempre participa con responsabilidad ejerciendo activamente sus derechos y deberes ciudadanos respecto al patrimonio cultural. En contraste, el $81 \%$ de los educandos del grupo control manifestó no hacerlo nunca (gráfico 16).

- En el ítem 9 el 95\% de los estudiantes del grupo experimental siempre respeta la diversidad del patrimonio cultural (bienes, actividades y creencias) manifestada dentro y fuera de la comunidad educativa, mientras que el $50 \%$ y el $38 \%$ de los discentes del grupo control precisaron que siempre y algunas veces, respectivamente (gráfico 17).

\begin{tabular}{|l|l|}
\hline $\begin{array}{l}\text { Gráfico 15. Reflexiona sobre la realidad } \\
\text { histórica y cultural local }\end{array}$ & $\begin{array}{l}\text { Gráfico 16. Participa de los derechos y deberes } \\
\text { cívico-patrimoniales }\end{array}$ \\
\hline $\begin{array}{l}\text { Ítem 7: ¿Usted reflexiona sobre la importancia, } \\
\text { cuidado, conservación y difusión de la }\end{array}$ & $\begin{array}{l}\text { Ít ¿Participa con responsabilidad ejerciendo } \\
\text { activamente sus derechos y deberes ciudadanos } \\
\text { historia de Pueblo Libre y de sus elementos } \\
\text { patrimoniales? }\end{array}$ \\
\hline
\end{tabular}
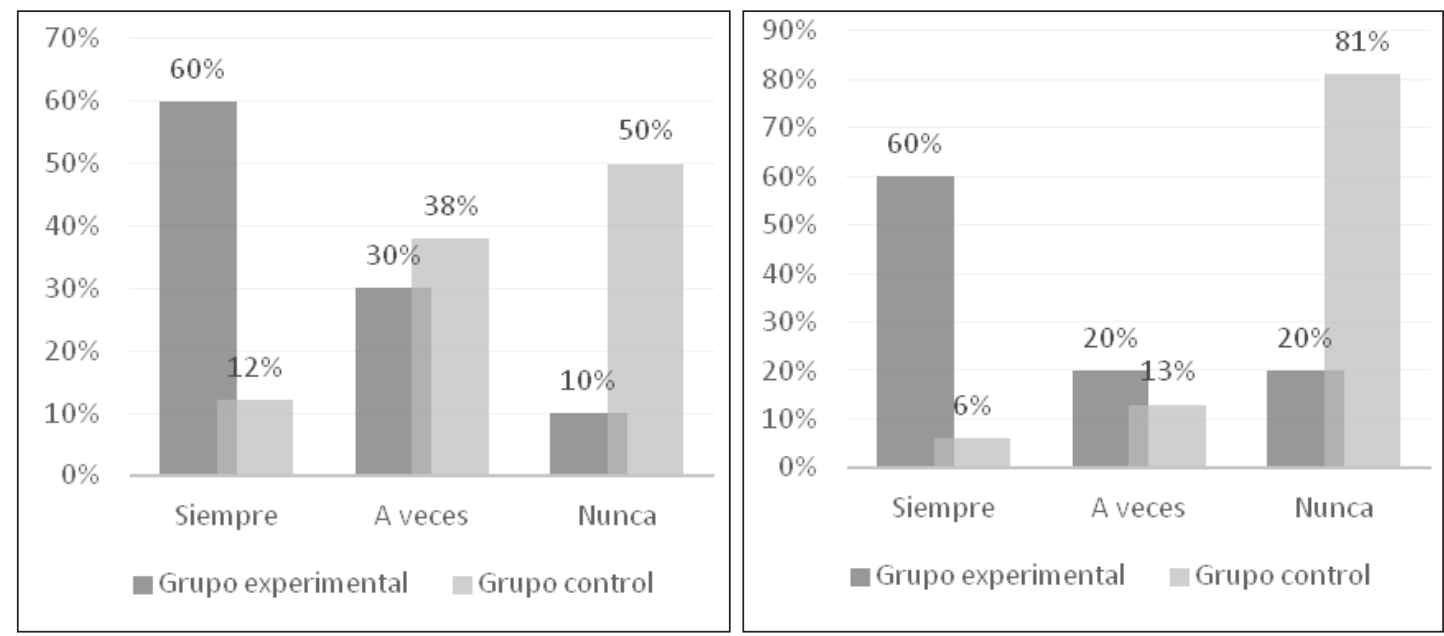

\section{Gráfico 17. Respeta la diversidad patrimonial}

íltem 9: ¿Usted respeta la diversidad del patrimonio cultural (bienes, actividades y creencias) manifestada dentro y fuera de la comunidad educativa?

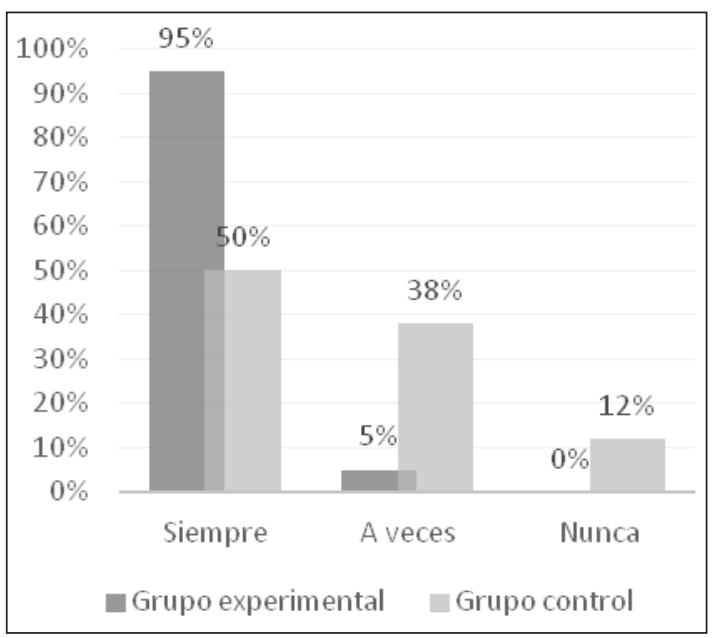




\section{* Dimensión actitudinal (saber ser)}

- En el ítem 18 el 80\% de los educandos del grupo experimental y el 69\% del grupo control sí han formulado preguntas y puntos de vista de manera asertiva durante el curso de patrimonio cultural mientras que el $20 \%$ y $31 \%$ de los educandos del primer y segundo grupo respectivamente no formularon estas preguntas y puntos de vista (gráfico 18).

- En el ítem 19 el 90\% de los alumnos del grupo experimental sí trabajó en equipo junto a sus pares de clase de manera ética con la finalidad de aprender colectivamente. Al contrario, el $57 \%$ de los estudiantes del grupo control precisó que no lo hacía (gráfico 19).

- En el ítem 20, el 100\% de los discentes del grupo experimental sí ha promovido la tolerancia y la sana convivencia en la comunidad educativa a pesar de las diferencias culturales, mientras que el $57 \%$ y $43 \%$ de los educandos del grupo control determinaron que sí y que no, respectivamente (gráfico 20).

\begin{tabular}{|l|l|}
\hline $\begin{array}{l}\text { Gráfico 18. Formula preguntas y puntos de } \\
\text { vista de manera asertiva }\end{array}$ & Gráfico 19. Trabaja en equipo con ética \\
\hline $\begin{array}{l}\text { Ítem 18: Ha formulado preguntas y puntos de } \\
\text { vista de manera asertiva durante el curso de } \\
\text { patrimonio cultural. }\end{array}$ & $\begin{array}{l}\text { Ítem Trabajó en equipo junto a sus } \\
\text { pares de clase de manera ética con la } \\
\text { finalidad de aprender colectivamente. }\end{array}$ \\
\hline
\end{tabular}
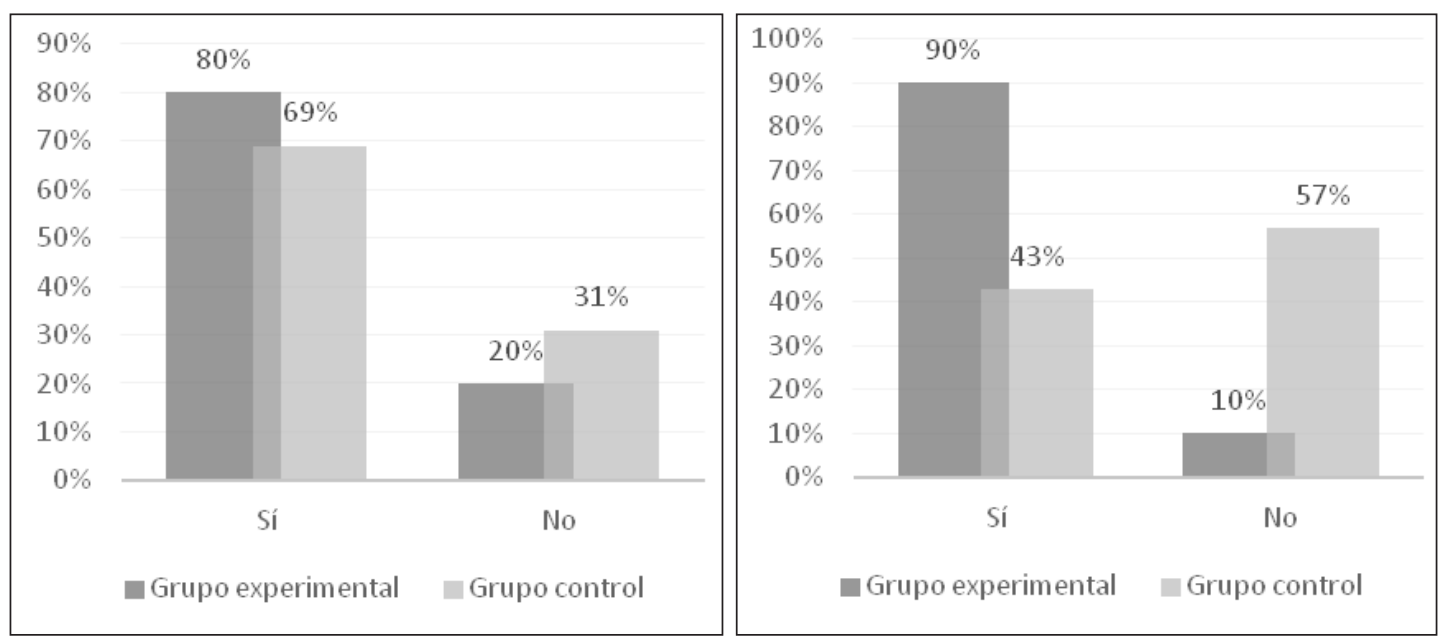


\section{Gráfico 20. Promueve la tolerancia y la sana convivencia \\ Ítem 20: Promovió la tolerancia y la sana convivencia en la comunidad educativa a pesar de las diferencias culturales.}

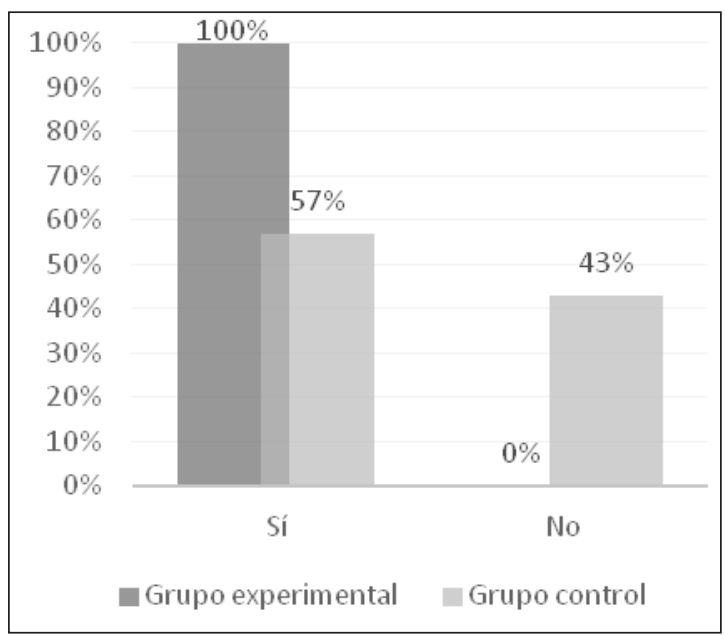

A continuación, en relación al análisis de datos se utilizó el programa IBM SPSS versión 20.0 para obtener el valor chi-cuadrado calculado $\left(\mathrm{X}_{c}^{2}\right)$ de cada ítem relacionado con la variable dependiente e independiente, con la intención de conocer si existen o no diferencias significativas entre el grupo control y el experimental dado que la investigación se enmarca dentro del análisis paramétrico debido a que "se define como parte de la estadística inferencial que ayuda al investigador a encontrar la significatividad de los resultados" (Ñaupas et al., 2014, p. 262). Por lo tanto se buscará alcanzar el objetivo general que es demostrar que el empleo de la educación patrimonial fortalece las CPI del alumnado de la asignatura de patrimonio cultural.

Seguidamente se analizaron los resultados de los ítems 1, 2 y 3 del cuestionario A1 de la dimensión enseñanza del patrimonio cultural local de la variable independiente y los ítems 10, 11, 12 y 13 de la lista de cotejo B1 de la dimensión cognitiva de la variable dependiente con la finalidad de lograr el objetivo específico 1.

En relación a la primera sección, los resultados muestran que los valores chi-cuadrado calculados son mayores a los tabulados $\left(X_{c}^{2}>X_{t}^{2}\right)$ y sus niveles de significancia son menores a 0.01, en particular en el caso de los ítems 2 y 3. Lo mismo se aprecia en el segundo grupo, particularmente en los ítems 11, 12 y 13. En consecuencia, se muestran diferencias significativas entre el grupo control y el experimental. No obstante, en los ítems 1 y 10 de los instrumentos de recolección de datos A1 y B1 respectivamente, se evidenció un escenario distinto ya que el valor chi-cuadrado calculado es menor al tabulado $\left(X_{c}{ }_{c}^{2}<X_{t}^{2}\right)$ y el nivel de significancia es mayor a 0.05. Por tanto no existen diferencias significativas entre los grupos de estudio manifestados a base de los ítems 1 y 10 (tabla 6).

Del mismo modo, se analizaron los resultados de los ítems 4, 5 y 6 del cuestionario A1 de la dimensión didáctica del patrimonio cultural de la variable independiente y los ítems 14, 15, 16 y 17 de la lista de cotejo B1 de la dimensión procedimental de la variable dependiente para alcanzar el objetivo secundario 2. Respecto al primer segmento, los resultados también precisan que los valores chi-cuadrado calculados son mayores a los tabulados $\left(X_{c}^{2}>X_{t}^{2}\right)$ y sus niveles de significancia son menores a 0.01. De igual forma se manifiesta el segundo 
segmento, específicamente en los ítems 15, 16 y 17. Por ende, se corroboran diferencias significativas entre el grupo control y el experimental como se ha verificado en el primer análisis. Por el contrario, en el ítem 14 de la herramienta B1 se exhibe un panorama distinto, puesto que el valor chi-cuadrado calculado es menor al tabulado $\left(X_{c}{ }^{2}<X_{t}^{2}\right)$ y el nivel de significancia es mayor a 0.05. En definitiva, no existen diferencias significativas entre los grupos de estudio señalados en relación al ítem 14 (tabla 6).

Por último se analizaron los resultados de los ítems 7, 8 y 9 del cuestionario A1 de la dimensión civismo de la variable independiente y los ítems 18, 19 y 20 de la lista de cotejo B1 de la dimensión actitudinal de la variable dependiente con el fin de lograr el objetivo específico 3. Acerca de la primera sección los resultados determinan que los valores chi-cuadrado calculados son asimismo mayores a los tabulados $\left(X_{c}{ }_{c}^{2} X_{t}^{2}\right)$ y sus niveles de significancia son menores a 0.01, lo que también se evidencia en la segunda sección, en particular en el caso de los ítems 19 y 20. Por tanto, se muestran diferencias significativas entre el grupo control y el experimental tal como se manifestó en el primer y en el segundo análisis. A pesar de ello, en el ítem 18 de la lista de cotejo B1 se apreció un contexto distinto pues el valor chi-cuadrado calculado es menor al tabulado $\left(X_{c}^{2}<X_{t}^{2}\right)$ y el nivel de significancia es mayor a 0.05. Por tanto, en el ítem enunciado no existen diferencias significativas entre los grupos de estudio citados (tabla 6).

Tabla 6: Chi-cuadrado calculado $\left(\mathrm{X}_{\mathrm{c}}{ }^{2}\right)$, Chi-cuadrado tabulado $\left(\mathrm{X}_{\mathrm{t}}{ }^{2}\right)$, grados de libertad (gl) y nivel de significancia ( $p$-valor) de cada pregunta

\begin{tabular}{|c|c|c|c|c|c|c|c|c|c|}
\hline Ítem & $\mathbf{X}_{\mathbf{c}}{ }^{2}$ & $\mathbf{X}_{\mathbf{t}}{ }^{2}$ & $\mathbf{g l}$ & $\mathbf{p}$-valor & Ítem & $\mathbf{X}_{\mathbf{c}}{ }^{2}$ & $\mathbf{X}_{\mathbf{t}}{ }^{2}$ & $\mathbf{g l}$ & $\mathbf{p}$-valor \\
\hline 1 & 1.39 & 5.99 & 2 & 0.499 & 11 & 22.4 & 3.84 & 1 & 0.000 \\
\hline 2 & 21.6 & 5.99 & 2 & 0.000 & 12 & 18.6 & 3.84 & 1 & 0.000 \\
\hline 3 & 25.3 & 5.99 & 2 & 0.000 & 13 & 25.3 & 3.84 & 1 & 0.000 \\
\hline 4 & 22.1 & 5.99 & 2 & 0.000 & 14 & 0.02 & 3.84 & 1 & 0.887 \\
\hline 5 & 25.3 & 5.99 & 2 & 0.000 & 15 & 28.4 & 3.84 & 1 & 0.000 \\
\hline 6 & 23.5 & 5.99 & 2 & 0.000 & 16 & 28.4 & 3.84 & 1 & 0.000 \\
\hline 7 & 10.4 & 5.99 & 2 & 0.005 & 17 & 28.4 & 3.84 & 1 & 0.000 \\
\hline 8 & 14.4 & 5.99 & 2 & 0.000 & 18 & 0.15 & 3.84 & 1 & 0.698 \\
\hline 9 & 9.73 & 5.99 & 2 & 0.007 & 19 & 6.91 & 3.84 & 1 & 0.008 \\
\hline 10 & 0.04 & 3.84 & 1 & 0.841 & 20 & 8.25 & 3.84 & 1 & 0.004 \\
\hline
\end{tabular}

Fuente: elaboración propia.

En cuanto a la discusión deben destacarse las metodologías activas tales como el ABP, el seminario o la casuística entre las más importantes dado que fomentan una cultura investigativa en los educandos. En esta misma línea, para enriquecer estas propuestas tradicionales se adaptó la educación patrimonial a una realidad peruana de educación formal y sus resultados son comparables a las estrategias investigativas propuestas por Cerda (2007) enmarcadas en el constructivismo debido a que la educación patrimonial transforma el aula en un escenario de aprendizaje activo y dinámico donde el alumnado construye su propio conocimiento y dinamiza los contenidos patrimoniales. De igual manera, dentro y fuera del aula se fomenta el trabajo en equipo con responsabilidad y ética, como ha sido propuesto por Poot (2013) en uno de los rasgos del ABP, pero como se establece en los ítems 10 y 18 la asimilación de estos contenidos y la participación de 
los educandos mediante la formulación de preguntas y puntos de vista, respectivamente, todavía pueden ser desarrollados por medio de las metodologías clásicas previamente citadas. Respecto a las CPI se han logrado resultados similares a las propuestas interdisciplinarias de Santacana (2018) y Quijano (2018; 2019) ya que el alumnado ha fortalecido sus capacidades expresadas en la estructuración del método hipotéticodeductivo así como en la identificación del problema, en la elaboración-aplicación de los instrumentos de recolección de datos y en la discriminación-sistematización de la información. Asimismo todo ello ha sido establecido por Cerda (2007), Miyahira (2009), Parra (2004) y Restrepo (2002) a través del uso de estrategias clásicas investigativas. Sin embargo, como ha sido señalado en el análisis del ítem 14, esta última capacidad puede ser lograda prescindiendo de la educación patrimonial, es decir, a partir de la utilización del ABP, según las conclusiones de Poot (2013).

Igualmente se han logrado conclusiones equivalentes a las investigaciones de Bardavio y Mañé (2017) por lo que se ha mejorado la comprensión y reflexión sobre la realidad sociocultural e histórica. En otras palabras, se ha cimentado el pensamiento crítico del estudiantado (Cerda, 2007; Miyahira, 2009; Parra, 2004; Restrepo, 2002). A pesar de esto, el entendimiento del patrimonio como constructo sociocultural es asimilado con o sin empleo de la educación patrimonial como figura en el ítem 1.

En lo referente a la selección del patrimonio cultural como objeto de estudio y problematización, está articulado de acuerdo a las conclusiones de las investigaciones de Bardavio y Mañé (2017) pues ha llevado al alumnado a la toma de decisiones en búsqueda de soluciones, tal como se manifiesta en la divulgación y/o comunicación de sus reportes finales de investigación, actividad pedagógica expresada en los trabajos de Calderón (2015). De la misma manera, en paralelo al fomento de las CPI se han desarrollado en los educandos competencias cívico-patrimoniales, tal como se precisa en los trabajos de Bardavio y González (2012) y Bardavio y Mañé (2017), referidas al ejercicio de los derechos y deberes con respecto al patrimonio cultural con el fin de cuidarlo, protegerlo y revalorarlo. En este marco es coincidente con las conclusiones de Cuenca (2014), Cuenca et al. (2011) y López y Cuenca (2014) en cuanto a que la educación patrimonial ha promovido el respeto a la diversidad cultural, la tolerancia y, por ello, la sana convivencia en la comunidad.

En suma, no solo se confirma el alto potencial de la educación patrimonial para desarrollar competencias cívico-patrimoniales, tal como ha sido fundamentado en las investigaciones de Cuenca (2014), Cuenca et al. (2011), Bardavio y González (2012), Bardavio y Mañé (2017) y López y Cuenca (2014), sino también se demuestra que es una metodología activa y pedagógica capaz de sembrar la cultura investigativa en el estudiantado alcanzando resultados equiparables a Cerda (2007), Miyahira (2009), Parra (2004) y Restrepo (2002).

\section{Conclusiones}

En base a los resultados empíricos se aprecia que el educando comprendió la realidad histórica y cultural de Pueblo Libre -Lima-Perú- al tiempo que utilizó su patrimonio local como objeto de estudio e identificó problemas de su entorno cultural inmediato. Gracias a ello desarrolló condiciones para conocer y estructurar el método hipotético-deductivo. De tal manera, se concluye que la enseñanza del patrimonio cultural local mejora significativamente la dimensión cognitiva de las CPI de los discentes de la asignatura de Patrimonio Cultural. 
Asimismo, con la ayuda de la aplicación de la educación patrimonial se ha dispuesto de un escenario de aprendizaje constructivista puesto que el estudiantado ha edificado su propio conocimiento mediante un cúmulo de actividades participativas que han impulsado la identificación, clasificación, interpretación e investigación del patrimonio cultural de Pueblo Libre. Estas estrategias han desarrollado la capacidad de elaboración y empleo de los instrumentos de recolección de datos, en particular en el caso de las encuestas y entrevistas dirigidas a la comunidad educativa. Incluso, resultados obtenidos por los propios estudiantes durante dicha investigación fueron procesados, redactados y difundidos por ellos mismos. Por estos motivos se concluye que la didáctica del patrimonio cultural desarrolla la dimensión procedimental de las CPI de los educandos.

De igual forma los educandos reflexionan sobre la realidad histórico-cultural de Pueblo Libre, en particular sobre su importancia y sobre el cuidado y conservación preventiva de los elementos patrimoniales para hacer uso del ejercicio ciudadano, es decir, de los deberes y valores patrimoniales. Esto se materializa dado que mantienen un respeto por la diversidad patrimonial y promueven la tolerancia y la sana convivencia en la comunidad educativa. Por último se fomenta el trabajo en equipo junto a sus compañeros de clase de manera ética con la finalidad de lograr un aprendizaje colectivo. Por todo lo mencionado el civismo fortalece significativamente la dimensión actitudinal de las CPI del alumnado.

Por consiguiente podemos concluir que el empleo de la educación patrimonial fortalece significativamente las CPI del alumnado de la asignatura Patrimonio Cultural debido a que se evidenciaron diferencias entre el grupo control y el experimental.

\section{Referencias bibliográficas}

Bardavio, A. y González, P. (2012). La adopción escolar de conjuntos patrimoniales: el programa PEAM de la Universidad Autónoma de Barcelona y el Camp d'Aprenentatge de La Noguera. En O. Fontal (ed.), I Congreso Internacional de Educación Patrimonial. Mirando a Europa: estado de la cuestión y perspectivas de futuro (pp. 331-341). Madrid: Instituto del Patrimonio Cultural de España.

Bardavio, A. y Mañé, S. (2017). La arqueología en la enseñanza obligatoria. El ejemplo del campo de aprendizaje de la Noguera. Otarq, 2, pp. 331-345. Recuperado de: http://revistas. jasarqueologia.es/index.php/otarq/article/view/127/128

Calderón, Y. (2015). Investigación formativa en el aula para la formación de actitud científica. Amazonía Investiga, 4(6), pp. 18-26. Recuperado de: https://www.amazoniainvestiga.info/ index.php/amazonia/article/view/679/639

Cázares, L. y Cuevas, J. (2007). Planeación y evaluación basadas en competencias. Fundamentos y prácticas para el desarrollo de competencias docentes, desde preescolar hasta el posgrado. México D.F.: Trillas.

Cerda, H. (2007). La investigación formativa en el aula. La pedagogía como investigación. Bogotá: Magisterio.

Coma, L. (2011). Actividades educativas y didácticas del patrimonio en las ciudades españolas. Barcelona: Universidad de Barcelona, Departamento de Didáctica de las Ciencias Sociales. Recuperado de: http://diposit.ub.edu/dspace/bitstream/2445/41467/20/01.LCQ TESIS.pdf

Cuenca, J. (2014). El papel del patrimonio en los centros educativos: hacia la socialización patrimonial. Tejuelo, 19, pp. 76-96. Recuperado de: https://dialnet.unirioja.es/descarga/ articulo/4725269.pdf 
Cuenca, J., Estepa, J. y Martín, M. (2011). El patrimonio cultural en la educación reglada. Patrimonio Cultural de España, 5, pp. 45-57. Recuperado de: https://www.researchgate.net/ profile/Jose_Lopez55/publication/260796786_El_patrimonio_cultural_en_la_educacion reglada/links/00b7d5325d05c7c880000000/El-patrimonio-cultural-en-la-educacion-reglada. pdf

Hernández, R., Fernández, C. \& Baptista, M. (2014). Metodología de la investigación (6. a ed.). México: McGraw-Hill.

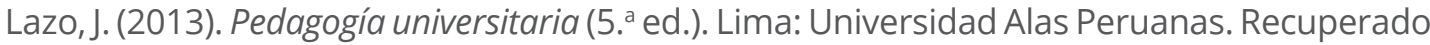
de: http://repositorio.uap.edu.pe/handle/uap/6118

Ley N. ${ }^{\circ} 30$ 220, Ley Universitaria. (8 de julio de 2014). En Diario Oficial El Peruano. Recuperado de: https://www.sunedu.gob.pe/wp-content/uploads/2017/04/Ley-universitaria-30220.pdf

López, I. y Cuenca, J. (2014). El patrimonio y las personas: símbolos e identidad cultural como elementos claves para la educación. En O. Fontal, A. Ibáñez, y L. Martín (Eds.), Il Congreso internacional de educación patrimonial: reflexionar desde las experiencias. Una visión complementaría entre Francia, España y Brasil, pp. 1161-1171. Madrid: Plan Nacional de Educación y Patrimonio. Recuperado de: http://www.culturaydeporte.gob. es/planes-nacionales/dam/jcr:90cfb441-c07f-4455-8032-1d6ea3074055/actas-ii-congresointernacional-ep.pdf

Miyahira, J. (2009). La investigación formativa y la formación para la investigación en el pregrado. Revista Médica Herediana, 20(3), pp. 119-122. DOI: https://doi.org/10.20453/rmh. v20i3.1010

Ñaupas, H., Mejía, E., Novoa, E. y Villagómez, A. (2014). Metodología de la investigación cuantitativa-cualitativa y redacción de la tesis (4. ${ }^{a}$ ed.). Bogotá: Ediciones de la U.

Parra, C. (2004). Apuntes sobre la investigación formativa. Educación y Educadores, 7 , pp. 57-77. Recuperado de: http://educacionyeducadores.unisabana.edu.co/index.php/ eye/article/view/549/642

Pérez, M. (2012). Fortalecimiento de las competencias investigativas en el contexto de la educación superior en Colombia. Revista de investigaciones UNAD, 11(1), pp. 9-34. Recuperado de: https://academia.unad.edu.co/images/investigacion/hemeroteca/ revistainvestigaciones/volumen 11 num $1 \% 202012 / 1 . \% 20$ Fortalecimiento\%20de\%20las\%20 competencias\%20investigativas\%20en\%20el\%20contexto\%20de\%20la\%20educacion\%20 superior\%20en\%20Colombia.pdf

Pimienta, J. (2012). Estrategias de enseñanza-aprendizaje. Docencia universitaria basada en competencias. México: Pearson.

Poot, C. (2013). Retos del aprendizaje basado en problemas. Enseñanza e Investigación en Psicología, 18(2), pp. 307-314. Recuperado de: http://www.redalyc.org/pdf/292/29228336007. pdf

Quijano, I. (2018). El uso de la arqueología experimental como recurso didáctico en el proceso de aprendizaje. Una experiencia educativa en estudiantes de administración turística de Lima, Perú. Educare, 22(3), pp. 1-27. DOI: https://doi.org/10.15359/ree.22-3.14

Quijano, I. (2019). Arqueología experimental y competencias pedagógicas investigativas. Una propuesta desde la educación patrimonial en el Perú. Mauricio: Editorial académica española. 
Restrepo, B. (2002). Concepto y aplicaciones de la investigación formativa y criterios para evaluar la investigación científica en sentido estricto. Bogotá: Consejo Nacional de Acreditación. Recuperado de: http://www.epn.edu.ec/wp-content/uploads/2017/03/Investigaci\%C3\%B3nFormativa-Colombia.pdf

Santacana, J. (2018). La arqueología y el reto de educar. En A. Egea, L. Arias y J. Santacana, Y la arqueología llegó al aula. La cultura material y el método arqueológico para la enseñanza de la historia y el patrimonio (pp. 9-21). Gijón: Trea.

* Universidad Nacional Mayor de San Marcos (Perú)

${ }^{1}$ Master en Educación con mención en Docencia Universitaria y Licenciado en Ciencias Sociales con especialidad en Arqueología, Universidad Nacional Mayor de San Marcos (Perú). Licenciado en Educación con especialidad en Ciencias Histórico Sociales (Perú). Profesor e investigador en educación patrimonial y su didáctica, arqueología experimental como recurso didáctico y museos pedagógicos. 